\title{
Organizational Initiatives for Promoting Employee Work-Life Reconciliation Over the Life Course. A Systematic Review of Intervention Studies
}

\section{Annina Ropponen'}

Adjunct Professor, Finnish Institute of Occupational Health, Finland

\section{Marja Känsälä}

PhD, Finnish Institute of Occupational Health, Finland

\section{Johanna Rantanen}

Adjunct Professor, Department of Teacher Education, University of Jyvaskyla, Finland

\section{Salla Toppinen-Tanner}

PhD, Finnish Institute of Occupational Health, Finland

\begin{abstract}
This review aimed to explore the initiatives, interventions, and experiments implemented by employing organizations and designed to support the work-life reconciliation at workplaces, and the effects of these actions on employees' well-being at work.

A systematic literature review was conducted on the basis of a search in Psyclnfo, ERIC, and the ISI Web of Science database of Social Sciences between January 2000 and May 20 I 5. Those studies were included in which either organizational or individual-level initiatives, interventions, or experiments were implemented by employers at workplaces in order to promote the work-life reconciliation of their employees. Work-life reconciliation was considered to encompass all life domains and all career stages from early to the end of working career.

The content analysis of 11 studies showed that effective employer actions focused on working time, care arrangements, and training for supervisors and employees. Flexibility, in terms of both working time and other arrangements provided for employees, and support from supervisors decreased work-family conflict, improved physical health and job satisfaction, and also reduced the number of absence days and turnover intentions.

Overall, very few intervention studies exist investigating the effects of employer-induced work-life initiatives. One should particularly note the conditions under which interventions are most successful, since many contextual and individual-level factors influence the effects of organizational initiatives on employee and organizational outcomes.
\end{abstract}

\section{KEY WORDS}

Employees, intervention, organization, wellbeing, work-life reconciliation, workplaces

DOI

10.19154/njwls.v6i3.5529

\footnotetext{
${ }^{1}$ E-mail: annina.ropponen@ttl.fi
} 


\section{Introduction}

he demands of work life, and the number of women, dual-earner couples, and single parents in the workforce have increased, and will continue to do so worldwide (Hammer et al., 2005; Kossek et al., 2010). Furthermore, in addition to taking care of children, an increasing number of employees are involved in caring for elderly parents or spouses (Ireson et al., 2016) and/or are caught between caring for both children and aging parents [i.e., sandwiched generation X; (Neal \& Hammer, 2007)]. The challenge of today's working adults is to find 'a satisfying, healthy, and productive life that includes work, play, and love' that is, performing a balancing act between different life domains (Kofodimos, 1993). Also, employers are challenged in their efforts to maintain a motivated, healthy, and skilled workforce.

Reconciliation of work and nonwork roles and demands has received a great deal of attention by research using first mainly negative concepts such as work-family conflict (Greenhaus \& Beutell, 1985). But after 1990s, this research area has vastly expanded and includes now several concepts and measures of work-family interface such as workfamily conflict, enrichment, balance, and fit (Casper et al., 2013; Kinnunen et al., 2014).

In our review, we follow the reasoning of Brough \& O'Driscoll (2010) and use the term work-life reconciliation as an upper construct for all the above-mentioned concepts describing interaction between work and life spheres. In our review, work-life reconciliation covers all these constructs describing and measuring the different aspects of it, that is, absence and presence of conflict or enrichment as well as lack or sufficiency of balance or fit between work and nonwork domains. Furthermore, a life-course perspective is applied, highlighting the career-long need to balance work and other areas of life from early to the end of working career, that is, including taking care of children, spouses, or elderly parents, as well as in the case of not having family or having in addition to family relations also heavy other outside work-life commitments such as participating volunteer working, serious time-consuming hobbies, or other activities. This broad approach is important in particular due to ongoing efforts to improve legislation in European Union to promote sustainable working life (Commission, 2015), but also because of still existing discrimination at work due to life situation (such as being mother or a single without children having different possibilities for working hours and taking vacations) (see, e.g., Dworkin et al., 2013; Lewis et al., 2008).

Particularly not only in the field of psychology but also in education and sociology, research on the work-life reconciliation over the last decades has shown that effective management of the demands arising from work and nonwork domains can have a significant effect on workers' satisfaction, health, and performance (Brough \& O'Driscoll, 2010; Eby et al., 2005; Ford et al., 2007; Hoobler et al., 2010; Kelly et al., 2008). Successful reconciliation of work and nonwork domains has important positive implications not only for individuals in the form of psychological improvements but also for organizations and society in general affecting thus economic and sociologic outcomes, such as productivity and obligation to organization (Beauregard \& Henry, 2009; Cascio $\&$ Boudreau, 2008; Eby et al., 2005). However, despite the often found positive shortterm effects for individuals utilizing work-life reconciliation measures in practice, they may also have negative consequences in terms of reduced earnings or career chances as examples. Furthermore, the consequences of application of work-life reconciliation options may differ in men and women both in short- and long-term (Halrynjo, 2009;

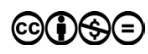


Russell et al., 2009; Smith et al., 2013; Straub, 2007). Hence, not only are intervention studies important in verifying hypothesized associations and effects between work and nonwork domains, but they also offer important knowledge for developing effective interventions for improving employee work-life reconciliation in the future. Furthermore, studies are warranted that apply multidisciplinary approach since either worklife reconciliation or interventions are not solely reflecting single domains but require actions that account the variety of life situations both at work and in private life.

To date, a growing body of literature, including several meta-analyses, suggest based on mostly on cross-sectional studies that job stress, family stress, and family conflict (Byron, 2005), social support at work (Kossek et al., 2011; Michel et al., 2011), work role stressors and involvement, work characteristics, and personality traits (Michel et al., 2011), and workplace flexibility (Allen et al., 2013) are key antecedents for work-family conflict and enrichment. Work-family conflict and enrichment in turn are considered as imposing negative and positive, respectively, consequences for the well-being of employees both at work and at home (McNall et al., 2010; Shockley \& Singla, 2011). These meta-analyses have thus aimed to explore the associations between antecedents, moderators and outcomes, and their effect on work-life reconciliation (Allen et al., 2013; Byron, 2005; Michel et al., 2011). Accordingly, these associations are expected to be found in the contents of organization-level interventions not only aimed to improve the work-life reconciliation of employees but also to clarify which kind of interventions are most beneficial in this endeavor.

When the aforementioned meta-analyses are reviewed more closely, they show that the specific associations of interest in terms of effect size and correlations have been at least one form of workplace flexibility, either flextime or flexplace, using 61 independent datasets (Allen et al., 2013); social support at the workplace in terms of work-family specific support and general perceptions of organizational support in 115 datasets (Kossek et al., 2011); job and family satisfaction but also job and family stress and support in 153 datasets (Shockley \& Singla, 2011); work-related, nonwork, and demographic factors such as working hours, job stress, family stress and support, and income using 65 datasets (Byron, 2005); and work role stressors (such as role conflict and time demands), work role involvement (work interest), social support at work (organizational and supervisor support), work characteristics (job autonomy), and personality (internal locus of control) in 178 samples (Michel et al., 2011). One meta-analysis investigated the effect of work-family enrichment on work-related, nonwork, and healthrelated outcomes in 21 independent datasets (McNall et al., 2010), indicating positive effects not only on work-related factors but also on physical and mental health. The variety of factors of interest and outcomes in these meta-analyses suggests that work-life reconciliation at workplace can be approached using different disciplines of even applying multidisciplinary approach.

The benefits of using longitudinal studies with quasi-experimental or experimental designs in work-family research have also been previously recognized (Hammer et al., 2011; Kelly et al., 2008; Kossek et al., 2011). In addition to longitudinal and experimental designs, less focus has also been paid to evaluating the effects of organizationallevel interventions for promoting work-life reconciliation (Brough \& O'Driscoll, 2010; Kelly et al., 2008). The company-level, employer-induced initiatives, or interventions of previous studies can be categorized as policies focusing on (1) the provision of employee services (fitness benefits etc.); (2) the provision of employee parental benefits (paid 
parental leave etc.,); (3) job restructuring, working time arrangements, and flexibility (part-time work, telework etc.); and (4) organizational development or training activities (leadership training, diversity training, etc.) (see Beauregard \& Henry, 2009; Brough \& O’Driscoll, 2010). Previous reviews have identified seven intervention studies (time period for literature searches 1987-2007) (Brough \& O'Driscoll, 2010), two studies (1971-2009) (Joyce et al., 2010), and three studies (2000-2013) (Skinner \& Chapman, 2013) for improving work-life reconciliation.

The perceived quality of work-life reconciliation can be seen as a first-hand outcome of the fit between the resources and demands created by the work environment, nonwork environment, and the employee's personal abilities and resources (the Work-Home Resources Model by ten Brummelhuis \& Bakker, 2012). In line with the Work-Home Resources Model, work-life reconciliation may be enhanced by increasing either workrelated or personal resources. Work-related resources can be enhanced through objective interventions (such as increasing flexibility), whereas personal resources require subjective interventions (such as training of coping skills). Personal resources may help in coping with the demands of environment, as well as utilizing other resources (ten Brummelhuis \& Bakker, 2012). Individual perception of work-life reconciliation is the mediator between initiatives and both employee health and well-being, and organizational outcomes (Kelly et al., 2008). Kelly et al. (2008) furthermore suggest that any workplace initiative aimed to enhance resources or to diminish demands should be considered, and not only formal workplace policies. In addition to organizational changes, individual-level interventions can be used, for example, to improve the ability to cope with conflicting demands arising between work and nonwork domains.

In sum, the objective of this review was to first provide an overview of the kind of initiatives and interventions that support employees' work-life reconciliation, and to describe the effects of these initiatives on employees' abilities and experiences about work-life reconciliation in their lives. Well-being at work was selected as a secondary outcome to capture the wide variety of measures to assess the effects of supporting work-life reconciliation. Moreover, the feeling of work-life reconciliation is not necessarily dependent on the existence of care responsibilities; it is a subjective feeling (Hammer et al., 2011). Further, the effects of work-life initiatives at workplace level are mediated via individual well-being, which then influences workplace-level outcomes (in terms of reduced costs and increased productivity) (Kelly et al., 2008). This is important, as workplaces usually invest in work-life reconciliation due to gain for their own benefit. In this review, the organizational interventions were defined as including any actions, policies, and initiatives implemented by work organizations to support work-life reconciliation, and to prevent or decrease negative interaction between work and other areas of life such as stress or dissatisfaction. The particular focus was on identifying actions taken by employers either at the organizational or individual level.

\section{Methods}

We conducted a systematic literature review to explore the effects of interventions at workplaces that aimed to promote the work-life reconciliation. In the review process of the potential articles, we applied a selection criterion that the relevant study should aim to investigate effects of any actions to promote or support work-life reconciliation 
at workplaces. The first part of this review was based on a literature search in PsycInfo and ERIC. The search was limited to studies published from January 1, 2000, to the end of May 2015. The search terms were intervention AND (work OR work organization) AND (family OR non-work OR private life OR care OR family-friendly OR elderly)'.

Because the first search resulted in only very few references to potential studies, and as we suspected that there might be more, we performed three other systematic literature searches. In the following searches, we used PsycInfo and the ISI Web of Science database of Social Sciences, following the procedure and criteria described above, but using the search terms 'experiments', 'action research', and 'longitudinal' as alternative search terms for 'intervention', respectively.

Furthermore, as a final step, we reviewed the references listed in identified publications for possible additional articles to include. We considered studies in English and all identified article titles were independently reviewed by two of the authors. On the basis of the titles, all relevant abstracts were also independently reviewed by two of the authors. Abstracts were randomly assigned and reviewers remained blind to each other's reviews. Criteria for inclusion for full article review were (1) full-text article in English; (2) intervention or longitudinal study; (3) workplace at the focus of the study; (4) outcome related to employees' perceptions of work-life reconciliation (and/or well-being at work); (5) a peer-reviewed journal article that contained original research. In cases of discrepancies between reviewers, a third reviewer made the tie-breaking decision regarding inclusion/exclusion.

The full article review phase included reapplying the inclusion criteria. All articles were reviewed by two reviewers and coded independently. If the decision to exclude was not unanimous, consensus was reached through discussion between the two reviewers. The main reasons for rejecting articles from this review were, in order of frequency, (1) the study did not include an intervention or an initiative, (2) the study did not focus on the work-life reconciliation, and (3) rather than having an outcome related to the worklife reconciliation, the study focused on describing factors that affected the work-life reconciliation. Eventually, we also included studies that evaluated changes in the perceived quality of work-life reconciliation in a longitudinal design, regardless of whether or not they used a control group. Due to wide variation in the designs, concepts, measures, and analysis strategies of the included studies, we were not able to make formal comparisons or conduct a meta-analysis of these articles. Hence, we conducted a content analysis with a critical review. The review included evaluation of studies that appeared to be relevant for quality, content and practices, or interventions for improving the worklife reconciliation at workplaces. We also considered the type of intervention according to Work-Home Resources Model whether it focused on fostering work-related (i.e., objective) or personal (i.e., subjective) resources that enhance work-life reconciliation. Figure 1 summarizes the Preferred Reporting Items for Systematic Reviews and MetaAnalyses (PRISMA) Flow Diagram (Moher et al., 2009), used to illustrate the flow of our literature research.

\section{Results}

The 11 studies included in the content analysis represented a variety of approaches to support the work-life reconciliation at workplaces (see Table 1). The number of 
Figure I: Flow diagram of literature searches in Psyclnfo, ERIC, and ISI Web of Science databases and article evaluation process. Adapted from Moher et al., 2009.
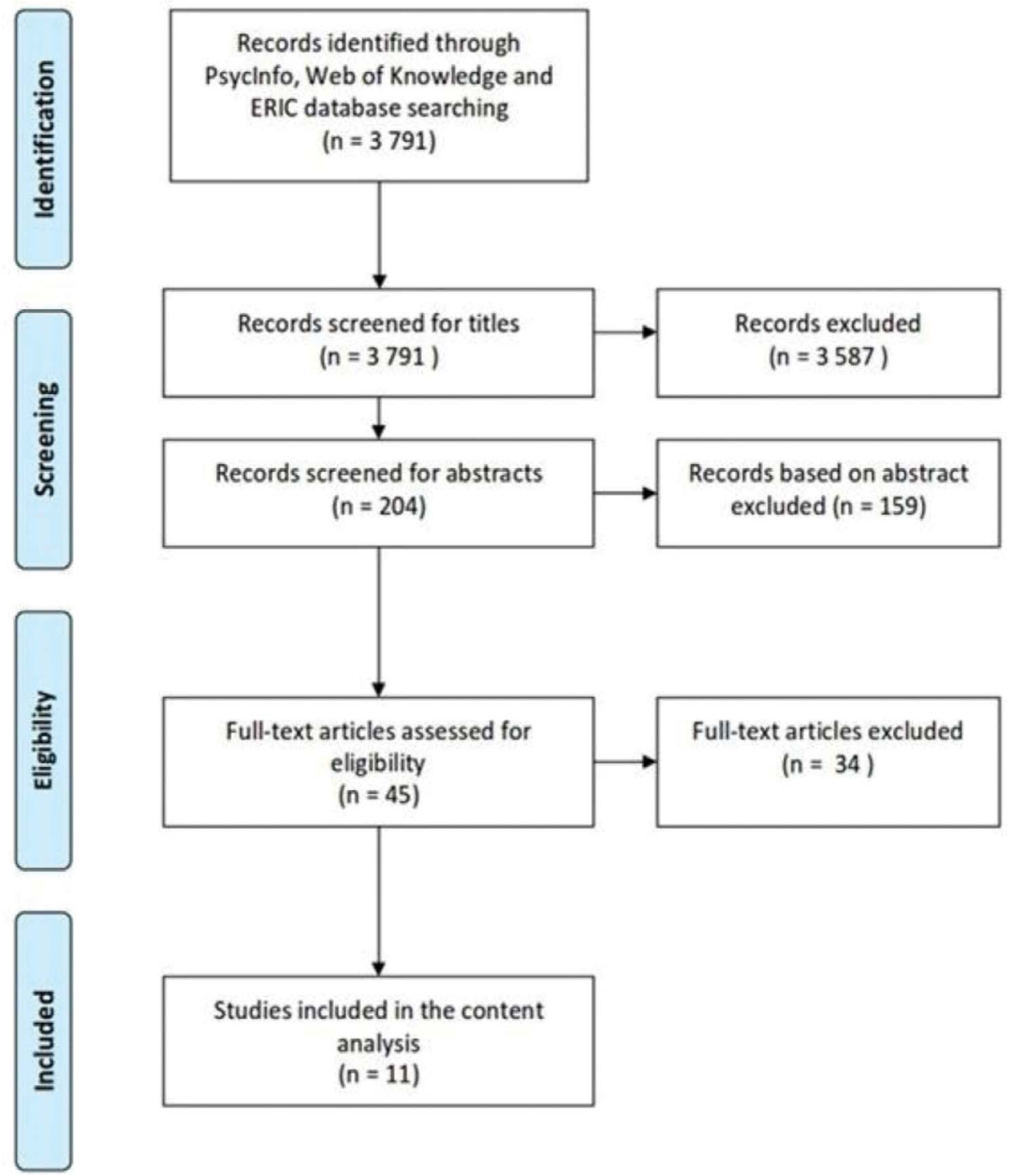

Out of nine studies that had an intervention, five studies had randomized group design (Haslam et al., 2013; Kelly et al., 2014; Martin \& Sanders, 2003; Michel et al., 2014; van Steenbergen et al., 2008). Only the intervention called STAR was performed at the organizational level being the only intervention with initiatives for both work-related and personal resources. STAR included supervisory training on strategies to demonstrate support for employees' personal and family lives, and job performance, and eight hours 


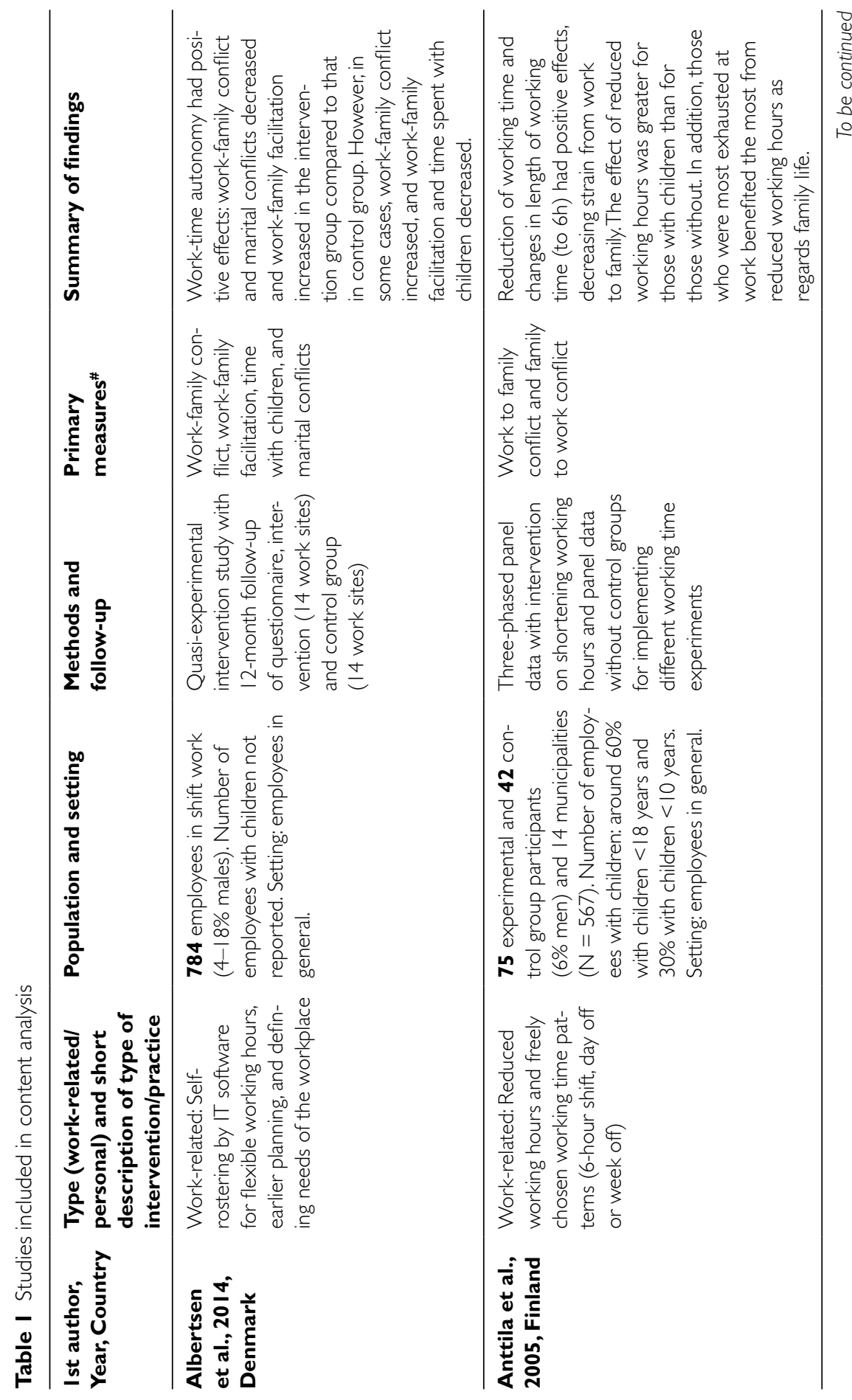




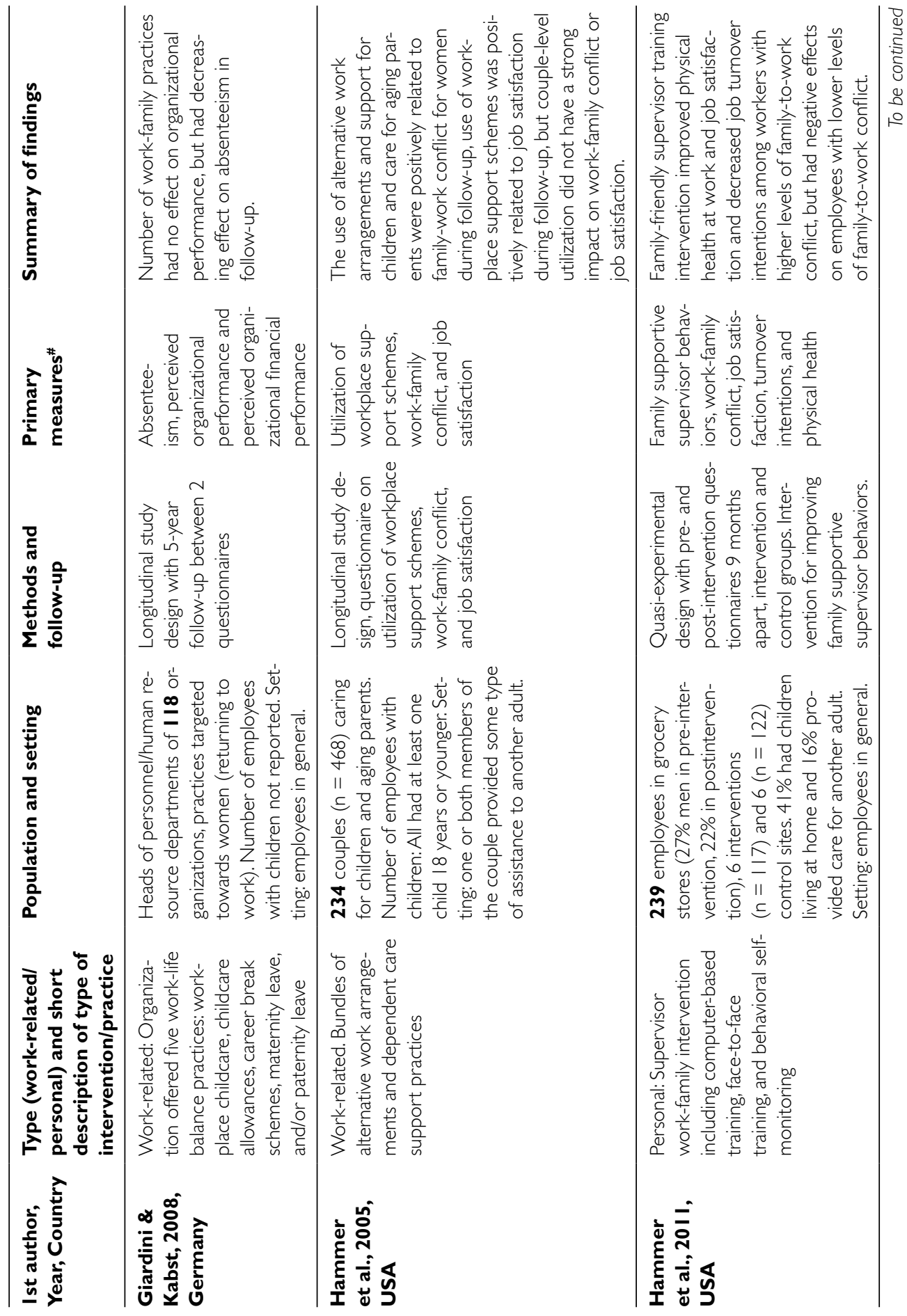




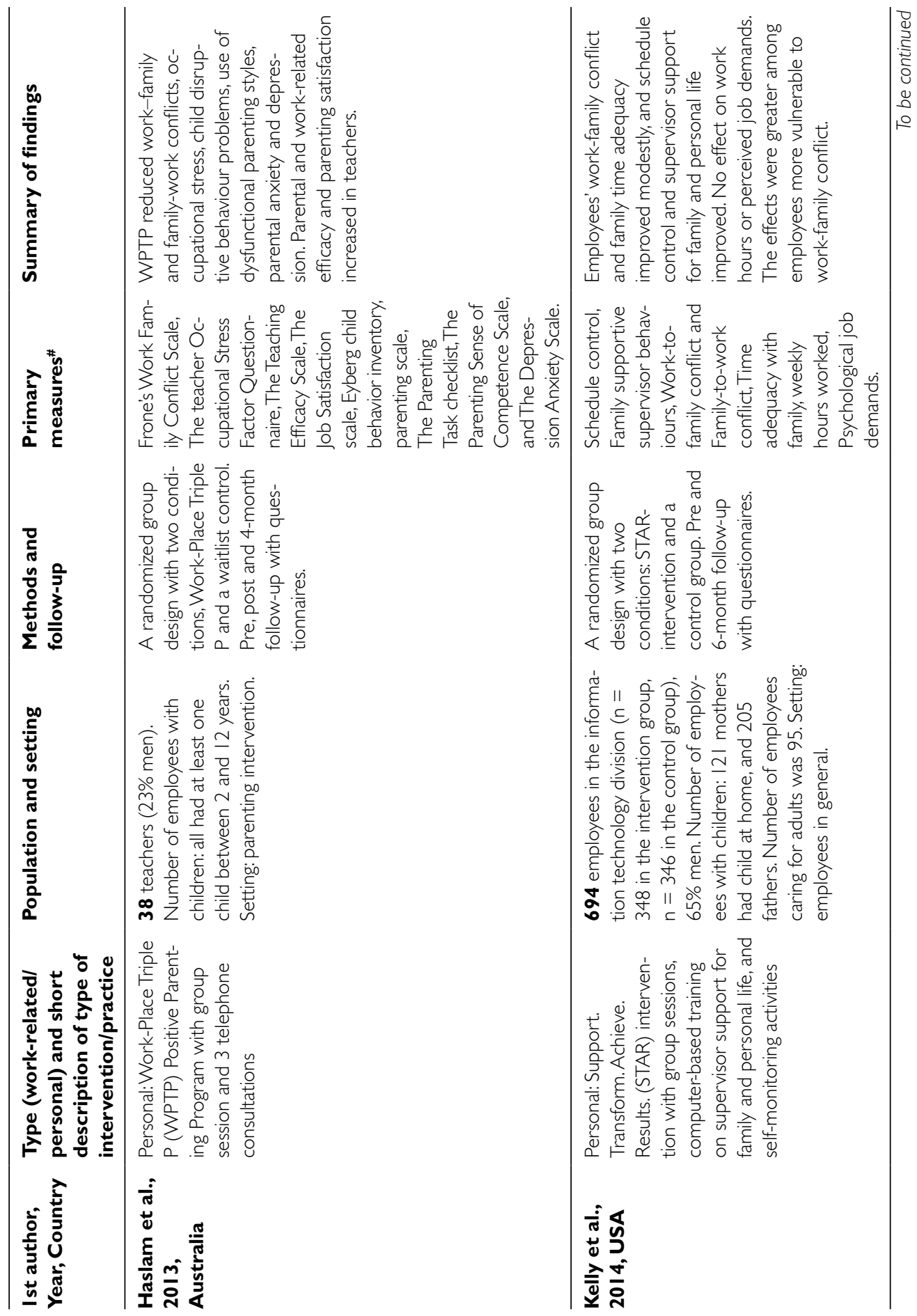




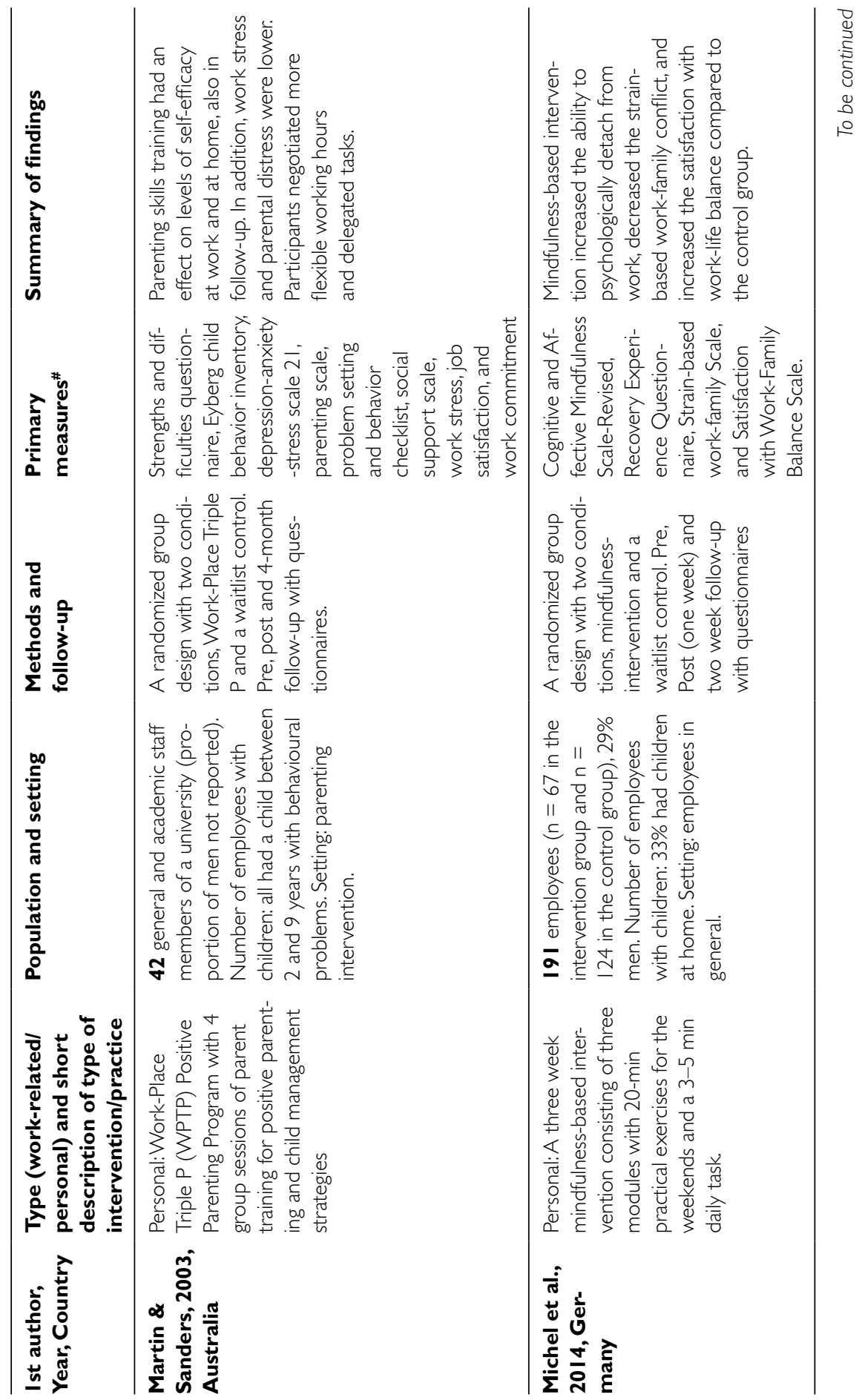




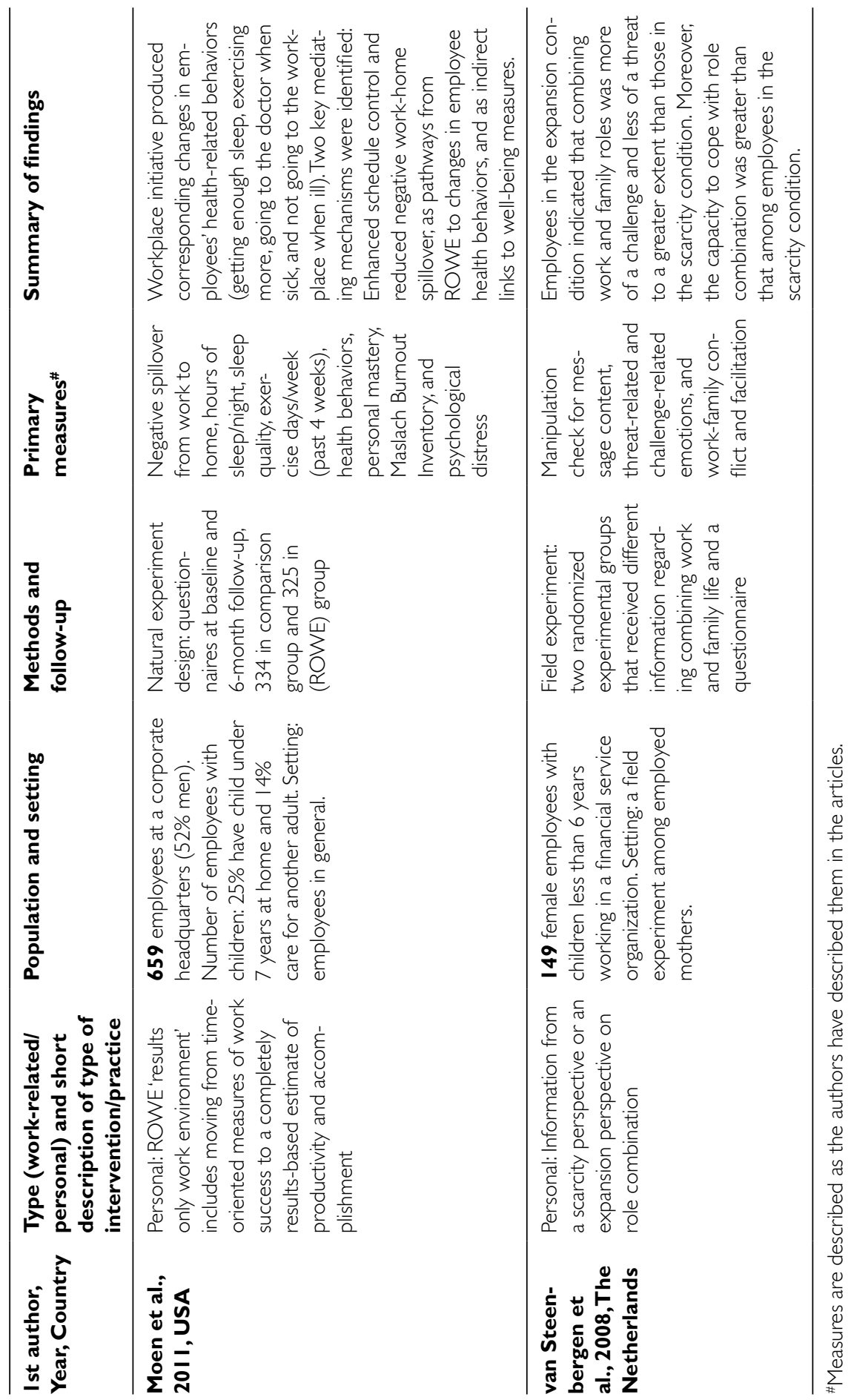


of participatory training sessions for employees to identify new work practices and processes to increase control over working hours and focus on key results. Furthermore, managers had an additional four hours of training (Kelly et al., 2014).

The interventions in the other randomized group designs were quite distinct: the studies by Martin \& Sanders (2003) and Haslam et al. (2013) applied focus on personal resources, Work-Place Triple $\mathrm{P}$, which includes four group sessions of parent training ( $2 \mathrm{~h} /$ session), four individual telephone consultations (15-30 $\mathrm{min} /$ consultation), and a group workbook; these all involved teaching parents 17 core positive parenting and child management strategies. Instead, the study by van Steenbergen et al. (2008) aimed to investigate whether cognitive appraisals regarding work-family role combination can be influenced by providing informational support for personal resources. The study included reading one of two articles about combining work and family life: One experimental group read an article on the role scarcity theory, and the other group an article on the role expansion theory on combining work and family roles. Furthermore, the study by Michel et al. (2014) investigated mindfulness-based intervention as a cognitiveemotional segmentation strategy (i.e., separate private life from work concerns) to promote work-life balance assessed with measures of strain-based work-family conflict and satisfaction with work-life balance. The intervention for personal resources consisted of three modules of online mindfulness exercises over three weeks.

The parenting, work stress and work-family conflict measures, and the outcomes of the above-introduced five randomized group design studies differed considerably. In all studies, the interventions appeared to have positive influences on the outcomes. The study by van Steenbergen et al. (2008), comprising 149 mothers with children less than 6 years of age working in financial services, showed that it is possible to influence the way in which employees cognitively appraise the combination of their work and family lives by providing informational support. In the study by Martin and Sanders (2003) in turn, 42 academics with child behavioral problems experienced lower levels of work stress after receiving parenting training, whereas the another study with Triple P indicated positive effects on work-to-family conflict, family-to-work conflict, occupational stress, and teaching efficacy among 38 teachers who were also parents with at least one child (Haslam et al., 2013). Among 694 employees of whom some had either a child at home or did care for adults, Kelly et al. (2014) yielded modest improvement in work-family conflict and having enough time for the family, but clear increases in schedule control and supervisor support for family and personal life. Also, the training of mindfulness had positive effects on increased satisfaction with work-life balance and psychological detachment from work during off-time among 246 employees (Michel et al., 2014). Any of these randomized group design studies that included both genders did not report gender differences.

Furthermore, three experimental design studies were identified by the systematic review. The first intervention was performed at the organizational level and included work-related resources through self-rostering (i.e., possibility to influence working hours and shifts in shift work based on the preferences of the employees) with computer software for increasing flexible working hours, early planning, and identifying the needs of the workplace (Albertsen et al., 2014). The study consisted of mainly hospitals and psychiatric wards, and aimed to investigate the impact of self-rostering on work-family conflict, work-family facilitation, time with children, and marital conflicts (Albertsen et al., 2014). Another study at the organizational level investigated whether 
a deliberate change in the temporal structure of work predicts changes in health-related outcomes, and whether personal resources by organizational initiatives for job redesign (i.e., work success will not be evaluated by working hours but by results-based appraisal of productivity and accomplishment) affect health outcomes through mechanisms of increasing employees' schedule control and/or reducing stressful work-family conflicts among employees of whom only $25 \%$ had small children (Moen et al., 2011b). The study by Hammer et al. (2011) included supervisor training for improving family supportive supervisor behaviors, in order to enhance the skills and motivation of supervisors to increase their interpersonal contact with employees and support their needs as regards managing the work-family interface. This was an employee-level study of grocery store supervisors and employees targeted at enhancing personal resources. Almost $50 \%$ of the participants had part-time contracts. The study aimed to investigate workfamily conflict among employees in order to determine the effects of a family-supportive supervisory training intervention on employee job satisfaction, turnover intentions, and physical health. Another goal was to examine how the perceptions of family supportive supervisor behaviors may mediate the moderating effects of work-family conflict on training outcomes (Hammer et al., 2011).

These experiments had quite large sample sizes, between 239 and 784, and setting of employees in general. None of the experiments reported gender differences. The follow-up times (after intervention) varied from 6 to 12 months. A comparison of the intervention and control groups in the studies indicated positive effects of the experiments: work-family conflict decreased, work and health improved among employees with higher levels of work-family conflict, negative work-home spillover decreased, and the number of absence days fell among employees who had either as many or more absences than employees on average in their workgroup.

One study included a work-related intervention, but the design was a panel study with an intervention and a control group, albeit at the organizational level (Anttila et al., 2005). The intervention included reduced working hours in three different ways: A six-hour working day, a day off, or a week off. The study investigated the effects of the three conditions on work-family conflict, and which of the reduced working time options had the most positive effect on work-family interaction. The results showed that work-family interaction decreased to a greater extent in the six-hour shift than in the other forms of reduced working hours.

The two studies that were included in this review but had no intervention were longitudinal studies with one and five-year follow-ups. Both studies had baseline and follow-up measurements. One of the studies focused on the heads of the personnel/ human resource departments (Giardini \& Kabst, 2008) and the other on couples caring for children and aging parents (Hammer et al., 2005), both at the individual level. The first study of work-related resources investigated whether the degree to which the organizations provide work-family practices is related to organizational performance and absenteeism (Giardini \& Kabst, 2008). The latter study, focusing on caring couples, investigated a mixture of initiatives for work-related and personal resources in assessing association between the individuals' use of alternative work arrangements or use of dependent care support, and individuals' work-to-family conflict and family-to-work conflict (Hammer et al., 2005). The results of both studies indicated that the alternative work arrangements, family-friendly workplace practices, and support for dependent care had a positive effect on the measured outcomes: absenteeism decreased (Giardini 
\& Kabst, 2008), job satisfaction increased, and work-family conflict decreased-more, however, among women than among men (Hammer et al., 2005).

\section{Summary of the results}

Five of the eleven studies comprising 38-784 individuals included in the content analysis had a randomized group design (Haslam et al., 2013; Kelly et al., 2014; Martin \& Sanders, 2003; Michel et al., 2014; van Steenbergen et al., 2008), three had an experimental design (Albertsen et al., 2014; Hammer et al., 2011; Moen et al., 2011a), two were longitudinal survey studies (Giardini \& Kabst, 2008; Hammer et al., 2005), and one was a panel study with an intervention (Anttila et al., 2005). Following the typology of the company-level initiatives or interventions (Beauregard and Henry, 2009, Brough and O'Driscoll, 2010), none of the studies included fit to the (1) the provision of employee services (fitness benefits etc.); two of the studies fit (2) the provision of employee parental benefits (paid parental leave etc.,); two of studies included (3) job restructuring, working time arrangements, and flexibility (part-time work, telework etc.); and seven of the studies had (4) organizational development or training activities (leadership training, diversity training, etc.). The intervention programs had positive influences on the cognitive appraisal of the perceived quality of work-life balance/reconciliation as well as on employee well-being: Work stress decreased and health improved, and negative work-home spillover and the number of absence days decreased. The results of the longitudinal studies indicate that alternative work arrangements, familyfriendly workplace practices and support for dependent care reduced absenteeism and work-family conflict, and increased job satisfaction, although gender differences were rarely evaluated. Another important aspect was that given the institutional context of the studies, three out of the four studies providing work-related initiatives (i.e., working time arrangements, support for dependent care) took place in Europe (Albertsen et al., 2014; Anttila et al., 2005; Giardini \& Kabst, 2008), whereas only one in USA (Hammer et al., 2005). Instead, studies aiming to enhance personal resources (training activities) took place in USA, Australia, and one in the Netherlands (Tab. 1).

\section{Discussion}

The aim of this review was to obtain an overview of recent studies (2000-May 2015) that reported on interventions for supporting work-life reconciliation at workplaces. These interventions focused particularly on describing the effects of organizational initiatives on, first and foremost, employees' perceptions of work-life reconciliation and, secondarily on well-being at work. This review included comprehensive literature searches from three literature databases, and systematic searches with four different combinations of search terms. Despite the rather large number of articles $(\mathrm{N}=3791)$ identified from the databases, only 11 articles fulfilled the inclusion criteria for the content analysis. This number of included articles is much lower than those reported in the meta-analyses of work-life reconciliation studies without intervention focus, which vary between 21 and 153 articles (Allen et al., 2013; Amstad et al., 2011; Byron, 2005; Kossek et al., 2011; McNall et al., 2010; Michel et al., 2011; Shockley \& Singla, 2011), but similar to the 
number (two to seven) of earlier reviews focusing specifically on intervention studies (Brough \& O'Driscoll, 2010; Joyce et al., 2010; Skinner \& Chapman, 2013). Hence, this difference is mainly due to the fact that earlier reviews and meta-analyses have focused on reporting accumulated information about the specific associations between different factors (antecedents, moderators, and outcomes) of work-family interface. This accumulated knowledge comes mostly from cross-sectional studies, whereas longitudinal and intervention studies tapping somewhat better cause-effect relationships are more rarely reported or even conducted at workplace level.

Five studies with a randomized controlled design, which often is considered the golden standard for studies on causal effects (Hernán, 2004), showed that work-life reconciliation interventions had positive effects on cognitive appraisal and work-related stress. Due to differences in sample size and interventions, and due to mixture of initiatives for work-related and personal resources, it was not possible to estimate the effect sizes or importance. However, the results of the studies with experimental designs support the findings of randomized controlled designs. Furthermore, it seems that initiatives for work-related resources (i.e., actions related to working time arrangements and dependent care) were influential within welfare states in Europe suggesting that beyond public child care, further actions to support work-life reconciliation are needed to support employees at work. Instead, the initiatives for personal resources (i.e., training of various types and target groups) showed efficacy in the countries without public health care and stronger social norms for longer working hours (Tab. 1), placing higher emphasis on fostering characteristics and abilities that enhance individual coping with the challenges of work life reconciliation. Despite the wide variety of interventions at different organizational levels (Albertsen et al., 2014; Hammer et al., 2005; Moen et al., 2011c), the large sample sizes further confirm positive effects: reduced work-family conflict and improved health among employees with initially higher levels of work-family conflict, and less negative work-home spillover and absence days.

\section{Limitations}

The search strategy included three databases, but was limited to studies written in English. However, according to an analysis of 159 systematic reviews (Egger et al., 2003), non-English and nonindexed trials tend to show larger treatment effects than others. Hence, it is unlikely that a missing study would significantly differ from the findings of this review. Another limitation is that only content analysis was performed without a meta-analysis. Although we cannot evaluate publication bias since we did not perform a meta-analysis, it may nevertheless exist in these studies, due to a relatively low number of high-quality trials in terms of randomized controlled design. Furthermore, we applied psychological orientation with a focus on subjective wellbeing at work in this review. Besides being a limitation due to lack of applicability to other disciplines, we would like to believe that this orientation would be important in order to identify influential organizational level initiatives for well-being consequently having an effect of workplace-level outcomes (such as reduced costs and increased productivity) as shown before (Cascio \& Boudreau, 2008; Kelly et al., 2008). Another important aspect missing in most studies was the evaluation of gender differences. Although some studies included in this review accounted the family type, number of children, and/or care for adults in 
the sample, results for gender differences in work-life reconciliation or well-being at work were rarely reported.

Furthermore, there seems to be a lack of availability of dependent care support in comparison to child care support at workplaces, as we found no intervention studies that focused on this specific situation among working employees (Hammer et al., 2005). Hence, a limitation of not only in this study but also among all studies of work-life reconciliation is the lack of intervention or longitudinal studies of other dependent care except for children, consequently preventing to assess the life-course perspective. Furthermore, both longitudinal and review studies show the benefits of, especially, employee working time control and flexibility for work-life reconciliation and job satisfaction, which were not included in our review, as they did not meet the inclusion criteria (Jansen et al., 2010; Nijp et al., 2012). It has been estimated that work-life issues in general will be an even more important part of human resources management in the future, as most people struggle with reconciling the demands arising from different life spheres during at least some phase of their working career (Hammer et al., 2014).

\section{Methodological implications}

The studies were conducted in different countries, presenting markedly different institutional contexts: The Nordic countries (Finland, Denmark), Central and Western Europe (Germany, the Netherlands), the United States of America (four studies), and Australia. The institutional context can have a significant impact on the effects of the interventions (Anttila et al., 2005; Giardini \& Kabst, 2008; Martin \& Sanders, 2003). Some interventions may not even be as applicable in other countries, and the baseline of the work-life reconciliation can be different. For example, in the Nordic welfare countries, public day care services are generous, the female employment rate is high, and although people have a sense of entitlement to work-life reconciliation, they do not really consider it the duty of organizations (Anttila et al., 2005; Giardini \& Kabst, 2008). Therefore, initiatives for work-related resources to give further support on work-life reconciliation such as working time arrangements or care for dependent are warranted. In Anglo-Saxon contexts, public welfare services regarding the worklife reconciliation are rare, working hours are long, and organizational family-friendly practices are more common and may have more effect (Giardini \& Kabst, 2008). However, this review indicates that initiatives for personal resources including individual or supervisor training may also be useful. Central and Western Europe are somewhere in between, with countries that are welfare states but in which women either stay at home to take care of the children more often than in the Nordic countries (Giardini \& Kabst, 2008), or frequently work part-time (van Steenbergen et al., 2008). Taking the socio-cultural context into consideration in the interpretation of the results is therefore important.

On the basis of the studies included in our review, several recommendations concerning the methodology of future studies may be required. For instance, future research should contain control groups and differentiate the effects of multiple component interventions, psychological mediating processes (Hammer et al., 2005), pre/ postintervention data behavioral measures (Hammer et al., 2005; van Steenbergen et al., 2008), quasi/field/natural experimental designs (Hammer et al., 2005; Moen et al., 
2011b; van Steenbergen et al., 2008), longitudinal data (Hammer et al., 2005; van Steenbergen et al., 2008), personality variables (van Steenbergen et al., 2008), randomized groups (Albertsen et al., 2014; Moen et al., 2011b), similar baselines between the groups (Albertsen et al., 2014), and large sample sizes (Giardini \& Kabst, 2008; Martin \& Sanders, 2003; Moen et al., 2011b). One issue when measuring the effects of interventions is time-lag, as some of the effects happen in the short-term and others in the long run (Albertsen et al., 2014; Hammer et al., 2011; Martin \& Sanders, 2003; Moen et al., 2011b). A wait-list control group may be used to reduce feelings of unfairness among the intervention and control group (Albertsen et al., 2014; Michel et al., 2014). Our review showed the benefits of teaching management of work and family life effectively to individuals or couples consequently improved work-life reconciliation. This kind of approach could be an important means by which to increase the balance in today's highly insecure, constantly changing work life.

\section{Practical implications}

Due to the limited number of studies, it is difficult to infer which specific contents the interventions should include in order to be effective. However, the results found in this review were in line with previous reviews that have focused on the organization-level effects of work-life balance support (Brough \& O’Driscoll, 2010; Kelly et al., 2008). The effective interventions found in this review not only focused both on initiatives for work-related resources including working time and care arrangements but also on personal resources as training for supervisors and employees (and parents of children with behavioral problems in particular) and even mindfulness training, at both the organizational and employee level. Although we did not find any studies that applied the provision of employee services (fitness benefits etc.) that would be for workrelated resources and being based on the typology of the company-level initiatives or interventions (Beauregard \& Henry, 2009; Brough \& O’Driscoll, 2010), there was almost equal distribution in studies with initiatives for work-related resources over the provision of employee parental benefits (paid parental leave etc.,); job restructuring, working time arrangements, and flexibility (part-time work, telework, etc.); and organizational development or training activities (leadership training, diversity training, etc.). The studies focusing on working time found that control over one's working hours is essential in order for working time arrangements to successfully support the work-life reconciliation, as long as it does not lead to overresponsibility and the intensification of employees' leisure time (Albertsen et al., 2014; Anttila et al., 2005). However, as these studies of working time were performed in Nordic countries with welfare state model, further studies are warranted to confirm the effects in other countries. As for personal resources, training, measuring behavioral change, a component to increase motivation in training and multiple stakeholder evaluations, is advisable and at least effective in countries with longer working hours and stay-at-home mothers (Hammer et al., 2011).

The main aim of the intervention and how it is communicated is significant: If interventions are targeted toward family-friendliness, the impact on work-life reconciliation is probably greater than if the main aim is, for example, increased productivity (Albertsen et al., 2014; Anttila et al., 2005). Employee support and participation in 
the intervention are also crucial (Albertsen et al., 2014). Moreover, a recurrent major organizational change may have more impact on the result than the intervention itself (Albertsen et al., 2014). Thus, we recommend that the intervention explicitly states work-life reconciliation as its aim, involves employees, and is timed for a period with no major reoccurring organizational changes such as major down-sizing, application of complete new organizational structure, or merger. Experiences from STAR intervention combining increased schedule control with supervisor training show that benefits for employees' work-life fit and organizational goals can be enhanced simultaneously even without backlashes in terms of increased work-family permeability and increased work hours (Kelly et al., 2014).

Work-life reconciliation should not be seen as a challenge for working mothers with small children only. Although it is possible that this group may need the most support, this perspective also sustains the idea that family-friendly practices are only women's issue both at the workplace and at home, increasing the household duties borne by women (Anttila et al., 2005; Hammer et al., 2005; Moen et al., 2011b). Moreover, the feeling of work-life reconciliation is not necessarily dependent on the existence of care responsibilities; it is a subjective feeling (Hammer et al., 2011). It is thus advisable to target the interventions toward both genders and to pay particular attention to men when communicating this topic (Hammer et al., 2005). Interventions could use the term 'work-life reconciliation' instead of 'family-friendly' and 'work-family' in order to avoid misconception. We also suggest that bundles of practices, rather than individual practices, are studied, because alternatives and combinations may capture more individual variation (Giardini \& Kabst, 2008; Hammer et al., 2005). From the life-course perspective, interventions should be offered to all employees in order to avoid the idea that the practices are targeted toward or favor employees with families (Hammer et al., 2011; Moen et al., 2011b).

\section{Conclusions}

Improving the work-life reconciliation is one approach to enhancing employees' well-being and managing psychosocial stress at workplaces at least among employees at the age of having school-aged or younger children. Work-life reconciliation can be influenced through different organizational initiatives targeted toward changing various aspects of the work environment, and toward providing support and information for employees that should be tailored to account for the differences of needs and possibilities within different sectors and employee groups. It is most likely that changes in working time or supervisor training also positively influence other areas of well-being, not only work-family reconciliation suggesting that interdisciplinary approach could be applied.

\section{Funding}

This study was financially supported by Ministry of Social Affairs and Health of Finland, grant number 71813008. JR was supported by grant from the Academy of Finland (138369).

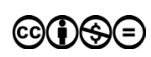




\section{References}

Albertsen, K., Garde, A. H., Nabe-Nielsen, K., Hansen, A. M., Lund, H. \& Hvid, H. 2014. Work-life balance among shift workers: results from an intervention study about self-rostering. International Archives of Occupational and Environmental Health, 87, 265-74. doi: http://dx.doi.org/10.1007/s00420-013-0857-x.

Allen, T. D., Johnson, R. C., Kiburz, K. M. \& Shockley, K. M. 2013. Work-family conflict and flexible work arrangements: deconstructing flexibility. Personnel Psychology, 66, 345-376. doi: http://dx.doi.org/10.1111/peps.12012.

Amstad, F. T., Meier, L. L., Fasel, U., Elfering, A. \& Semmer, N. K. 2011. A meta-analysis of work-family conflict and various outcomes with a special emphasis on cross-domain versus matching-domain relations. Journal of Occupational Health Psychology, 16, 151-69. doi: http://dx.doi.org/10.1037/a0022170.

Anttila, T., Nätti, J. \& Väisänen, M. 2005. The experiments of reduced working hours In Finland. Community, Work \& Family, 8, 187-209. doi: http://dx.doi.org/10.1080/ 13668800500049704.

Beauregard, T. A. \& Henry, L. C. 2009. Making the link between work-life balance practices and organizational performance. Human resource management review, 19, 9-22. doi: http://dx.doi.org/10.1016/j.hrmr.2008.09.001.

Brough, P. \& O'driscoll, M. 2010. Organizational interventions for balancing work and home demands: An overview. Work \& Stress: An International Journal of Work, Health \& Organisations, 24, 280-297. doi: http://dx.doi.org/10.1080/02678373.2010.506808.

Byron, K. 2005. A meta-analytic review of work-family conflict and its antecedents. Journal of Vocational Behavior, 67, 169-198. doi: http://dx.doi.org/10.1016/j.jvb.2004.08.009.

Cascio, W. F. \& Boudreau, J. W. 2008. Investing In People: Financial Impact of Human Resource Initiatives, New Jersey, USA, FT Press.

Casper, W. J., De Hauw, S. \& Wayne, J. H. 2013. Concepts and measures in the work-family interface: implications for work-family integration. In: Major, D. A. \& Burke, R. (eds.) Handbook of Work-Life Integration Among Professionals. Northampton, USA: Edwar Elgar. doi: http://dx.doi.org/10.4337/9781781009291.00011.

Commission, E. 2015. Roadmap: New start to address the challenges of work-life balance faced by working families.

Dworkin, T. M., Ramaswami, A. \& Schipani, C. A. 2013. The role of networks, mentors, and the law in overcoming barriers to organizational leadership for women with children. Michigan Journal of Gender and Law, 20, 83-123. doi: 10.2139/ssrn.2388674.

Eby, L., Casper, W., Lockwood, A., Bordeaux, C. \& Brinley, A. 2005. Work and family research in IO/ OB: Content analysis and review of the literature (1980 - 2002). Journal of Vocational Behavior, 66, 124-197. doi: http://dx.doi.org/doi:10.1016/j.jvb.2003.11.003.

Egger, M., Juni, P., Bartlett, C., Holenstein, F. \& Sterne, J. 2003. How important are comprehensive literature searches and the assessment of trial quality in systematic reviews? Empirical study. Health Technology Assessment, 7, 1-76. doi: http://dx.doi.org/10.3310/ hta7010.

Ford, M. T., Heinen, B. A. \& Langkamer, K. L. 2007. Work and family satisfaction and conflict: A meta-analysis of cross-domain relations. The Journal of Applied Psychology, 92, 57-80. doi: http://dx.doi.org/10.1037/0021-9010.92.1.57.

Giardini, A. \& Kabst, R. 2008. Effects of work-family human resource practices: a longitudinal perspective'. The International Journal of Human Resource Management, 19, 2079-2094. doi: http://dx.doi.org/10.1080/09585190802404312.

Greenhaus, J. H, Beutell N. J. Sources of Conflict between Work and Family Roles. 1985. The Academy of Management Review, 10, 76-88. doi: http://dx.doi.org/10.5465/ AMR.1985.4277352. 
Halrynjo, S. 2009. Men's Work-life Conflict: Career, Care and Self-realization: Patterns of Privileges and Dilemmas. Gender, Work \& Organization, 16, 98-125. doi: http://dx.doi. org/10.1111/j.1468-0432.2008.00432.x.

Hammer, L. B., Kossek, E. E., Anger, W. K., Bodner, T. \& Zimmerman, K. L. 2011. Clarifying work-family intervention processes: the roles of work-family conflict and family-supportive supervisor behaviors. Journal of Applied Psychology, 96, 134-50. doi: http://dx.doi. org/10.1037/a0020927.

Hammer, L. B., Neal, M. B., Newsom, J. T., Brockwood, K. J. \& Colton, C. L. 2005. A longitudinal study of the effects of dual-earner couples' utilization of family-friendly workplace supports on work and family outcomes. Journal of Applied Psychology, 90, 799-810. doi: http://dx.doi.org/10.1037/0021-9010.90.4.799.

Hammer, L. B., Van Dyck, S. E. \& Ellis, A. M. 2014. Organizational policies supportive of work-life integration. In: MAJOR, D. A. \& BURKE, R. (eds.) Handbook of Work-Life Integration Among Professionals. Cheltenham: Edgar Elgar. doi: http://dx.doi.org/10.43 37/9781781009291.00026.

Haslam, D., Sanders, M. \& Sofronoff, K. 2013. Reducing Work and Family Conflict in Teachers: A Randomised Controlled Trial of Workplace Triple P. School Mental Health, 5, 70-82. doi: http://dx.doi.org/10.1007/s12310-012-9091-z.

Hernán, M. A. 2004. A definition of causal effect for epidemiological research. Journal of Epidemiology and Community Health, 58, 265-271. doi: http://dx.doi.org/10.1136/ jech.2002.006361.

Hoobler, J. M., Hu, J. \& Wilson, M. 2010. Do workers who experience conflict between work and family domains hit a 'glass ceiling'?: A meta-analytic examination. Journal of Vocational Behavior, 77, 481-494. doi: http://dx.doi.org/10.1016/j.jvb.2010.07.001.

Ireson, R., Sethi, B. \& Williams, A. 2016. Availability of caregiver-friendly workplace policies (CFWPs): an international scoping review. Health Soc Care Community. doi: http:// dx.doi.org/10.1111/hsc.12347.

Jansen, N. W., Mohren, D. C., Van Amelsvoort, L. G., Janssen, N. \& Kant, I. 2010. Changes in working time arrangements over time as a consequence of work-family conflict. Chronobiology international, 27, 1045-1061. doi: http://dx.doi.org/10.3109/07420528 .2010 .489874 .

Joyce, K., Pabayo, R., Critchley, A. J. \& Bambra, C. 2010. Flexible working conditions and their effects on employee health and wellbeing. Cochrane Database of Systematic Reviews. doi: http://dx.doi.org/10.1002/14651858.CD008009.pub2.

Kelly, E. L., Kossek, E. E., Hammer, L. B., Durham, M., Bray, J., Chermack, K., Murphy, L. A. \& Kaskubar, D. 2008. Getting There from Here: Research on the Effects of Work-Family Initiatives on Work-Family Conflict and Business Outcomes. Academic Management Annual, 2, 305-349. doi: http://dx.doi.org/10.1080/19416520802211610.

Kelly, E. L., Moen, P., Oakes, J. M., Fan, W., Okechukwu, C., Davis, K. D., Hammer, L. B., Kossek, E. E., King, R. B., Hanson, G. C., Mierzwa, F. \& Casper, L. M. 2014. Changing Work and Work-Family Conflict: Evidence from the Work, Family, and Health Network. American Sociological Review. doi: http://dx.doi.org/10.1177/0003122414531435.

Kinnunen, U., Rantanen, J., Mauno, S. \& Peeters, M. 2014. Work-family interaction. In: Peeters, M., De Jonge, J. \& Taris, T. (eds.) An introduction to contemporary work psychology. Wiley Blackwell.

Kofodimos, J. 1993. Balancing act, San Francisco, Jossey Bass.

Kossek, E. E., Lewis, S. \& Hammer, L. B. 2010. Work-life initiatives and organizational change: Overcoming mixed messages to move from the margin to the mainstream. $\mathrm{Hu}$ man Relations, 63, 3-10.

Kossek, E. E., Pichler, S., Bodner, T. \& Hammer, L. B. 2011. Workplace social support and work-family conflict: A meta-analysis clarifying the influence of general and 
work-family-specific supervisor and organizational support. Personnel Psychology, 64, 289-313. doi: http://dx.doi.org/10.1111/j.1744-6570.2011.01211.x.

Lewis, J., Knijn, T., Martin, C. \& Ostner, I. 2008. Patterns of Development in Work/Family Reconciliation Policies for Parents in France, Germany, the Netherlands, and the UK in the 2000s. Social Politics: International Studies in Gender, State \& Society, 15, 261-286. doi: http://dx.doi.org/10.1093/sp/jxn016.

Martin, A. J. \& Sanders, M. R. 2003. Balancing Work and Family: A Controlled Evaluation of the Triple P- Positive Parenting Program as a Work-Site Intervention. Child and Adolescent Mental Health, 8, 161-169. doi: http://dx.doi.org/10.1111/1475-3588.00066.

Mcnall, L., Nicklin, J. \& Masuda, A. 2010. A Meta-Analytic Review of the Consequences Associated with Work-Family Enrichment. Journal of Business and Psychology, 25, 381-396. doi: http://dx.doi.org/10.1007/s10869-009-9141-1.

Michel, A., Bosch, C. \& Rexroth, M. 2014. Mindfulness as a cognitive-emotional segmentation strategy: An intervention promoting work-life balance. Journal of Occupational and Organizational Psychology, 87, 733-754. doi: http://dx.doi.org/10.1111/ joop. 12072.

Michel, J. S., Kotrba, L. M., Mitchelson, J. K., Clark, M. A. \& Baltes, B. B. 2011. Antecedents of work-family conflict: A meta-analytic review. Journal of Organizational Behavior, 32, 689-725. doi: http://dx.doi.org/10.1002/job.695.

Moen, P., Kelly, E. L. \& Hill, R. 2011a. Does Enhancing Work-Time Control and Flexibility Reduce Turnover? A Naturally Occurring Experiment. Social problems, 58, 69-98. doi: http://dx.doi.org/10.1525/sp.2011.58.1.69.

Moen, P., Kelly, E. L., Tranby, E. \& Huang, Q. 2011b. Changing work, changing health: can real work-time flexibility promote health behaviors and well-being? Journal of Health \& Social Behavior, 52, 404-29. doi: http://dx.doi.org/10.1177/0022146511418979.

Moen, P., Kelly, E. L., Tranby, E. \& Huang, Q. 2011c. Changing work, changing health: can real work-time flexibility promote health behaviors and well-being? Journal of health and social behavior, 52, 404-429. doi: http://dx.doi.org/10.1177/0022146511418979.

Moher, D., Liberati, A., Tetzlaff, J., Altman, D. G. \& Group, T. P. 2009. Preferred Reporting Items for Systematic Reviews and Meta-Analyses: The PRISMA Statement. PLoS Med, 6, e1000097. doi: http://dx.doi.org/10.1371/journal.pmed.1000097.

Neal, M. B. \& Hammer, L. B. 2007. Working couples caring for children and aging parents: Effects on work and well-being, Mahwah, NJ, Lawrence Erlbaum Associates.

Nijp, H. H., Beckers, D. G., Geurts, S. A., Tucker, P. \& Kompier, M. A. 2012. Systematic review on the association between employee worktime control and work-non-work balance, health and well-being, and job-related outcomes. Scand J Work Environ Health, 38, 299-313. doi: http://dx.doi.org/10.5271/sjweh.3307.

Russell, H., O'connell, P. J. \& Mcginnity, F. 2009. The Impact of Flexible Working Arrangements on Work-life Conflict and Work Pressure in Ireland. Gender, Work \& Organization, 16, 73-97. doi: http://dx.doi.org/10.1111/j.1468-0432.2008.00431.x.

Shockley, K. M. \& Singla, N. 2011. Reconsidering Work-Family Interactions and Satisfaction: A Meta-Analysis. Journal of Management, 37, 861-886. doi: http://dx.doi. org/10.1177/0149206310394864.

Skinner, N. \& Chapman, J. 2013. Work-life balance and family friendly policies. Evidence Base, 1-25.

Smith, N., Smith, V. \& Verner, M. 2013. Why are So Few Females Promoted into CEO and Vice President Positions? Danish Empirical Evidence, 1997-2007. Industrial \& Labor Relations Review, 66, 380-408. doi: http://dx.doi.org/10.1177/001979391306600204.

Straub, C. 2007. A comparative analysis of the use of work-life balance practices in Europe: Do practices enhance females' career advancement? Women in Management Review, 22, 289-304. doi: http://dx.doi.org/10.1108/09649420710754246. 
Ten Brummelhuis, L. L. \& Bakker, A. B. 2012. A resource perspective on the work-home interface: the work-home resources model. Am Psychol, 67, 545-56. doi: http://dx.doi. org/10.1037/a0027974.

Van Steenbergen, E. F., Ellemers, N., Haslam, S. A. \& Urlings, F. 2008. There is nothing either good or bad but thinking makes it so: Informational support and cognitive appraisal of the work-family interface. Journal of Occupational and Organizational Psychology, 81, 349-367. doi: http://dx.doi.org/10.1348/096317908X312669. 